thromboembolism, hemolysis, and mechanical failure, could be minimized if the maturation period were shortened. We have reported that both unfractionated and low molecular weight heparin accelerate pulmonary vascular maturation in neonatal rabbits by $250 \%$ and that this was characterized by significantly lower PA pressure at 2 weeks of age. ${ }^{19}$ Further development of this "chemo-mechanical lung assist" strategy might facilitate a paradigm shift in the surgical treatment of hypoplastic left heart syndrome. Many issues remain to be explored before this strategy can be applied clinically.

\section{Study Limitations}

There are certain limitations in this study. First, this is not a true cyanotic single ventricle model, but rather a high PVR cavopulmonary shunt model. Therefore, this study provided little data regarding the effects of MCPA on systemic hemodynamic, metabolism, and oxygenation and ventilation in a functional single ventricle physiology. Second, the short duration of the study provided little data regarding the possibility of long-term cavopulmonary assist using this type of system. A long-term study will be required to focus on, among other factors, anticoagulation, thrombosis, and pump sustainability. Third, the banded SVC, which was successfully dilated with a balloon catheter, may not be so simply dilated after long-term mechanical assist. Finally, the band placed on the SVC prevented circular flow from the PA to the SVC in the MCPA group. It also prevented retrograde flow in the SVC from right ventricular ejection. Because this is a $1 \frac{1}{2}$-ventricle model, the control animals would have had retrograde flow in the SVC during right ventricular ejection. As such, the control animals' cerebral physiology would be different from a single ventricle model of a high PVR cavopulmonary connection.

\section{CONCLUSIONS}

MCPA maintained BCPS flow, thereby sustaining the $1 \frac{1}{2}$-ventricle repair physiology with reasonable systemic hemodynamics and metabolism in neonatal pigs. This approach also maintained cerebral blood flow and metabolism by efficiently decompressing SVC pressure and maintaining an adequate transcerebral pressure gradient. This study conceptually raises the possibility of a primary BCPS creation in neonates with the aid of MCPA followed by catheter-based explantation of the pump system.

We thank Lisa Davey, Marvin Estrada, Lauren McKeeman, Stephen Y. Ta-min, and Satoko Uematsu for their technical support. We also thank Nobuko Yamamoto for her excellent illustrations.

\section{References}

1. Azakie T, Merklinger SL, McCrindle BW, Van Arsdell GS, Lee KJ, Benson LN, et al. Evolving strategies and improving outcomes of the modified Norwood procedure: a 10-year single-institution experience. Ann Thorac Surg. 2001;72: 1349-53.
2. Mahle WT, Spray TL, Wernovsky G, Gaynor JW, Clark BJ 3rd. Survival after reconstructive surgery for hypoplastic left heart syndrome: a 15-year experience from a single institution. Circulation. 2000;102(19 Suppl 3): III136-41.

3. Stasik CN, Goldberg CS, Bove EL, Devaney MD, Ohye RG. Current outcomes and risk factors for the Norwood procedure. J Thorac Cardiovasc Surg. 2006; 131:412-7.

4. Mahle WT, Spray TL, Gaynor JW, Clark BJ. Unexpected death after reconstructive surgery for hypoplastic left heart syndrome. Ann Thorac Surg. 2001; 71:61-5.

5. Bartram U, Grunenfelder J, Van Praaph R. Causes of death after the modified Norwood procedure: a study of 122 postmortem cases. Ann Thorac Surg. 1997;64: 1795-802.

6. Norwood WI, Kirklin JK, Sanders SP. Hypoplastic left heart syndrome: experience with palliative surgery. Am J Cardiol. 1980;45:87-91.

7. Reddy VM, Liddicoat JR, Hanley FL. Primary bidirectional superior cavopulmonary shunt in infants between 1 and 4 months of age. Ann Thorac Surg. 1995;59: 1120-5.

8. Bradley SM, Mosca RS, Hennein HA, Crowley DC, Kulik TJ, Bove EL. Bidirectional superior cavopulmonary connection in young infants. Circulation. 1996; 94(9 Suppl):II5-11.

9. Takatani S, Hoshi H, Tajima K, Ohuchi K, Nakamura M, Asama J, et al. Feasibility of a miniature centrifugal rotary blood pump for low-flow circulation in children and infants. ASAIO J. 2005;51:557-62.

10. Evans N, Kluckow M, Simmons M, Osborn D. Which to measure, systemic or organ blood flow? Middle cerebral artery and superior vena cava flow in very preterm infants. Arch Dis Child Fetal Neonatal. 2002;87:F181-4.

11. Chang AC, McKenzie ED. Mechanical cardiopulmonary support in children and young adults: extracorporeal membrane oxygenation, ventricular assist devices, and long-term support devices. Pediatr Cardiol. 2005;26:2-28.

12. Stiller B, Weng Y, Hubler M, Lemmer J, Nagdyman N, Redlin M, et al. Pneumatic pulsatile ventricular assist devices in children under 1 year of age. Eur Cardiothorac Surg. 2005;28:234-9.

13. Rodriguez RA, Cornel G, Austin EH, Auden SM, Weerasena NA. Brain function monitoring during bidirectional Glenn procedures. J Thorac Cardiovasc Surg. 2000;119:617-9.

14. Merklinger SL, Honjo O, Al-Radi OO, Poe J, Wang JZ, Van Arsdell GS. An animal model of mechanical lung assist for primary in-series palliation of hypoplastic left heart syndrome. Circulation. 2006;114:II544-5.

15. Carteauz JP, Roux S, Siaphy M, Schjoth B, Dolofon P, Bechamps Y, et al. Acute pulmonary hypertension after cardiopulmonary bypass in pig: the role of endogenous endothelin. Eur J Cardiothorac Surg. 1999;15:346-52.

16. Kido K, Hoshi H, Watanabe N, Kataoka H, Ohuchi K, Asama J, et al. Computational fluid dynamics analysis of the pediatric tiny centrifugal blood pump (TinyPump). Artif Organs. 2006;30:392-9.

17. Patel S, Allaire PE, Wood HG, Song X, Throckmorton AL, Untaroiu A, et al. Axial flow blood pumps. ASAIO J. 2003;49:255-64

18. Hanke T, Notzold A, Olschewski M, Siegenthaler MP, Brehm K, Strecker T, et al. The Impella Recover microaxial left ventricular assist device reduced mortality for postcardiotomy failure: a three-center experience. $J$ Thorac Cardiovasc Surg. 2004;127:812-22.

19. O’Blenes SB, Merklinger SL, Jegatheeswaran A, Campbell A, Rabinovitch M, Rebeyka I, et al. Low molecular weight heparin and unfractionated heparin are both effective at accelerating pulmonary vascular maturation in neonatal rabbits. Circulation. 1003;108(Suppl 1):II161-6.

\section{Discussion}

Dr William Gaynor (Philadelphia, $\mathrm{Pa}$ ). Why did you use the $1 \frac{1}{2}$-ventricle model? Why not ligate the main PA? In your no-assist group the PA is not banded, thus the right ventricle is able to eject and you are going to have a high SVC pressure. Basically, by banding the assist group you are just looking at a pump decompression of the SVC. It does not seem like a fair comparison of the two groups. Why not clamp the main PA and look at a pure superior cavopulmonary connection model rather than a $1 \frac{1}{2} 2$-ventricle model?

Dr Honjo. Thank you for your question. There are a couple of reasons why we used this model. The advantage of this 
model is that we can actually separate the cerebral circulation from the systemic circulation, looking at the effect of the pump system on the cerebral circulation and the metabolism. However, the disadvantage, as you mentioned, is that this is not a single ventricle model, meaning this is not a cyanotic model. We cannot compare the systemic oxygenation or ventilation. We have actually done the single ventricle model in which we created the single left ventricle under CPB with a cavopulmonary shunt as the primary blood source. That essentially showed that mechanical support extended the survival and also improved carbon dioxide exchange and oxygenation. However, because we had to use CPB, which deteriorates the systemic metabolism, that is not a good model to compare the cerebral perfusion in a fine way. That is why in this particular study we used this model.
Dr Y. Joseph Woo (Philadelphia, $\mathrm{Pa}$ ). With the way you displayed your model, depending on the flow rate that you establish within your pump, you could establish some degree of a closed loop circulation. How did you titrate how tightly to band the SVC to prevent such a closed loop circulation?

Dr Honjo. That is a very good question. This SVC band is very tight, because we do not want retrograde flow getting into the pump system, which makes a noneffective circulation. We do not want to occlude the SVC because we would eventually use it for a cavopulmonary shunt. However, this SVC band that we use is very tight. This is one of the disadvantages of using this pump system. Actually, if you use a different pump system, like a small axial pump, you can insert it into the SVC, and we do not need such a band. It might be beneficial, but we do not have a pump small enough to be inserted into the SVC. 